\title{
Theoretical Study of a Thermal Photovoltaic Hybrid Solar Collector
}

\author{
Boureima Dianda ${ }^{1 *}$, Thierry Sikoudouin Maurice $\mathrm{KY}^{2}$, Emmanuel Ouedraogo ${ }^{3}$, \\ Koami Soulemane Hayibo ${ }^{2}$ and Dieudonné Joseph Bathiebo² \\ 'Institute of Research in Applied Science and Technologies 03BP 7047 Ouagadougou 03, Burkina Faso; \\ diand8fr@gmail.com \\ ${ }^{2}$ University Ouaga 1 Professor Joseph KI-ZERBO 03 B.P. 7021, Ouagadougou, Burkina Faso; \\ thierrysmky@gmail.com, koami10@yahoo.fr, djbathiebo@gmail.com \\ ${ }^{3}$ University of Ouahigouya, Burkina Faso; \\ ouedem7@gmail.com
}

\begin{abstract}
Objectives: The purpose of this work is to determine and compare a PVT, PV panels and thermal collector's theoretical performances. Methods/Statistical Analysis: These different performances had been determined by establishing thermal balances at different levels of the system. The obtained equations had been discretized; simplifying hypotheses had been issued to ease their resolution. We adopted the Cholesky method using MATLAB software to solve these equations. The electrical, thermal and global efficiencies had been obtained. Comparisons based on these results had been made on these different panels. Findings: The temperature evolution of the system shows a heat-up of the PV cells. In the other hand, a speed increase of the wind brings a cooling of the collector. The increase of the coolant flow implies a decrease of the coolant temperature. This parameter, usually downplayed, showed to be very important. The profile of power curves show that hybrid panel's power is superior to simple PV panel and its thermal power is inferior to that of a thermal collector. However, the global efficiency of the hybrid panel is the highest. Most of these results confirm those of the literature while other results bring more information. Application/Improvements: Such a system could allow collecting the heat produced by the PV panels for water heating systems and more, with an optimization of the coolant flow for a better result.
\end{abstract}

Keywords: Efficiency, Power, PV Panel, PVT Panel, Thermal Collector

\section{Introduction}

The Sun is an abundant and renewable source of energy. The energy obtained from the Sun by the Earth is used by humans in different forms. Since then, humans have always used solar energy for either natural lighting or for heating or drying. More recently, several conversion technologies have emerged for more efficient use of this energy, particularly photovoltaic technology and thermal technology.

Photovoltaic technology makes it possible to obtain electricity through solar photovoltaic modules that capture solar energy and convert it into electricity by photovoltaic effect. PV panels convert solar energy into electrical energy with efficiency ranging from 5 to $20 \%$.
That means that more than $80 \%$ of the incident energy is lost as heat. This heating of the panels has a negative effect on their performances since the power obtained decreases with the rise in temperature. Studies were then conducted and systems were designed for the recovery and reuse of this heat.

A Photovoltaic Thermal collector (PVT) is a hybrid solar collector that converts some of the solar energy captured into electricity and recovers the other, usually lost as heat; that is cogeneration. This recovered heat is generally used for heating but can also be used for other purposes. This relatively new technology has already been the subject of several research projects, some of which are listed below.

*Author for correspondence 
A global inventory of hybridsolar collectors PVT based on reports ofthe European PV-Catapult project had been made. Among the studies identified, some focus on the evolution of the geometric configuration of the components and others, on the modeling methods. A comparison of the different configuration of PVT panel's efficiency had been done. A study on the influence of temperature under conditions of fluid stagnation demonstrated that in Europe, when the temperature goes beyond $135^{\circ} \mathrm{C}$, the risk of delamination of the EVA layer in the PV module increases enormously. Although stagnation is not common in the collector, special attention should be given to this phenomenon 1 . A PVT collector covered with a glass present a thermal efficiency of about $70 \%$. In the other hand, a PVT collector not covered has a thermal efficiency of around $60 \%$. By comparing the electrical efficiencies of the two panels to those of an ordinary PV panel, we notice that the PVT uncovered panel has the best efficiency and the PVT covered panel, the worst efficiency 2 . The influence of internal and external parameters on the electrical and thermal performances of PVT panels had also been studied. From that study, its comes that the increase of the distance between the heat transfer fluid pipes and that of the wind speed favors the heat dissipation from the PV panel.That allows to improve the electrical and thermal performances of these collectors ${ }^{3}$. Recent observations would partially contradict this conclusion.

Indeed, some authors used the finite elements to study the temperature profile of air PVT collectors. From their study, it comes that performance of the collector decrease with the increase of the wind speed ${ }^{4}$. A study held in 2013 showed that the increase of the wind speed or the increase of the depth of air channel brings thermal and global efficiencies dissipation of the system. That study also allowed determining an optimum insulation thickness of $0.1 \mathrm{~m}^{5}$.

In 2015, researchers conducted an exegetic and economic study of a PVT collector marketed under different climatic conditions in Iran.The exergy study is used to determine not only the amount of energy produced, but also its quality. A modeling of the system on Matlab and TRNSYS enabled them to show that the system is economically viable especially in marginalized areas. It also showed that the performances of a PVT system are extremely linked to climatic conditions of the area of implementation ${ }^{6}$. Recently, the thermal and electrical per- formances analysis of two types of solar hybrid air PVT collectors that can be integrated into roofs of buildings had been conducted. Two models are proposed, namely a model of hybrid PVT with the PV cells isolated with a confined air gap and anothermodel of hybrid PVT having an insulation made of an evacuated gap.

A modeling of heat transfer in $2 \mathrm{D}$ system, and in transient mode matching the nodal approach had been conducted. It comes out that the hybrid PVT vacuum collector is thermally more efficient than the one with the confined air layer. An optimal flow maintained by a fan also makes the system electrically efficient ${ }^{?}$.

The present study is consistent with the same logic as those cited above to improve the performances of PVT systems. This study is a numerical simulation study under MATLAB.

\section{Description of the Device}

The hybrid PVT "water collector" consists from top to bottom of:

- A PV module.

- An absorbing plate.

- Water circulation tubes.

- A layer of insulation at the back.

\subsection{The PV Module}

The PV module groups the glass on the front face, the PV cell layer and a tedlar layer. It turns solar energy into electricity. As its conversion ratio is low, much of this energy is converted into heat and transmitted to the tedlar layer. In a conventional PV panel, the tedlar's layer is cooled by the ambient air which is in contact with it. But in hybrids PVT, this tedlar's layer cooled by an absorbing plate.

\subsection{The Absorbing Plate and the Coolant}

The absorbing plate receives the heat produced by the panel through its coolant, and is responsible for transmitting it to the water through a system of tubes welded under the plate. Those tubes are of the same nature as the latter. The nature of the plate is decisive for the efficiency of the system. We will use galvanized steel whichhave good coefficient of heat absorption and low production $\operatorname{cost}^{\underline{8}}$. The physical properties of galvanized steel are given in Table 1. 
Table 1. Physical properties of galvanized steel

\begin{tabular}{|l|c|c|c|}
\hline Material & $\begin{array}{c}\text { Thermal } \\
\text { conductivity } \\
(\mathrm{W} / \mathrm{m} . \mathrm{K})\end{array}$ & $\begin{array}{c}\text { Weight heat } \\
(\mathrm{J} / \mathrm{kgK})\end{array}$ & $\begin{array}{c}\text { Density } \\
\left(\mathrm{kg} / \mathrm{m}^{3}\right)\end{array}$ \\
\hline Galvanizedsteel & 65 & 465 & 7833 \\
\hline
\end{tabular}

\subsection{Insulation Material}

As with any thermal system, insulation helps prevent heat loss in the surrounding air. It must be chosen so that its outside temperature is close to the ambient temperature. The insulation we have chosen is glass wool which physical properties are given in Table 2.

Table 2. Physical properties of glass wool

\begin{tabular}{|l|c|c|c|}
\hline Material & $\begin{array}{c}\text { Thermal } \\
\text { conductivity } \\
(\mathrm{W} / \mathrm{m} . \mathrm{K})\end{array}$ & $\begin{array}{c}\text { Weightheat } \\
(\mathrm{J} / \mathrm{kgK})\end{array}$ & $\begin{array}{c}\text { Density } \\
\left(\mathrm{kg} / \mathrm{m}^{3}\right)\end{array}$ \\
\hline Laine de verre & 0.036 & 40 & 840 \\
\hline
\end{tabular}

\subsection{Model Used}

\section{Thermal Analysis of the Collector}

The study is done to determine the temperatures of the different layers as well as the electric and thermal power produced and the corresponding yields. The transient heat transfer equations are described below. The principle of conservation of energy is used for each element.

\subsection{Outer Face of the Glass}

The outer face of the glass receives solar energy. It loses some of it by convection with the environment, another part by radiation with the sky (celestial vault) and transmits a part by conduction to its inner face.

$$
\begin{aligned}
m_{v} C P_{v} \frac{d T_{v, \text { ext }}}{d t}= & A_{v} G_{i}-h_{v-a}^{\text {conv }} A_{v}\left(T_{v, \text { ext }}-T_{a}\right) \\
& -\varepsilon_{v} \sigma A_{v}\left(T_{v, \text { ext }}^{4}-T_{\text {ciel }}^{4}\right) \\
& -h_{v}^{\text {cond }} A_{v}\left(T_{v, \text { ext }}-T_{a}\right)
\end{aligned}
$$

In this Equation, the temperature of the celestial vault is related to that of the ambient by relation:

$$
T_{\text {ciel }}=0.0552 T_{a}^{1.5}
$$

\subsection{Inner Face of the Glass}

$$
\begin{aligned}
m_{v} C P_{v} \frac{d T_{v, \text { int }}}{d t}= & A_{v} G_{i} \tau_{v}+h_{v}^{\text {conv }} A_{v}\left(T_{v, \text { ext }}-T_{v, \text { int }}\right) \\
& -h_{c e l}^{\text {cond }} A_{v}\left(T_{v, \text { int }}-T_{c e l}\right)
\end{aligned}
$$

\subsection{The Solar Cell}

$$
\begin{aligned}
m_{c e l} C P_{c e l} \frac{d T_{c e l}}{d t}= & A_{v} G_{i}\left(\tau_{v} a_{c e l}-\eta_{P V}\right) \\
& +h_{c e l}^{\text {cond }} A_{v}\left(T_{v, \text { int }}-T_{c e l}\right) \\
& -h_{\text {ted }}^{\text {cond }} A_{v}\left(T_{c e l}-T_{\text {ted }}\right)
\end{aligned}
$$

\subsection{The Layer of Tedlar}

$$
\begin{aligned}
m_{\text {ted }} C P_{\text {ted }} \frac{d T_{\text {ted }}}{d t}= & h_{\text {ted }}^{\text {cond }} A_{v}\left(T_{\text {cel }}-T_{\text {ted }}\right) \\
& -h_{a b s}^{\text {cond }} A_{v}\left(T_{\text {ted }}-T_{a b s}\right)
\end{aligned}
$$

\subsection{Absorbing Plate (absorber)}

$$
\begin{aligned}
m_{a b s} C P_{a b s} \frac{d T_{a b s}}{d t}= & h_{a b s}^{\text {cond }} A_{v}\left(T_{\text {ted }}-T_{a b s}\right) \\
& -h_{\text {tube }}^{\text {cond }} A_{a b s-t u b e}\left(T_{a b s}-T_{\text {tube }}\right) \\
& -h_{\text {iso }}^{\text {cond }} A_{a b s-i s o}\left(T_{a b s}-T_{i s o}\right)
\end{aligned}
$$

3.6 The Tube

$$
\begin{aligned}
m_{\text {tube }} C P_{\text {tube }} \frac{d T_{\text {tube }}}{d t}= & h_{\text {tube }}^{\text {cond }} A_{\text {abs-tube }}\left(T_{\text {abs }}-T_{\text {tube }}\right) \\
& -h_{f}^{\text {conv }} A_{\text {tube }-f}\left(T_{\text {tube }}-T_{f}\right) \\
& -h_{\text {iso }}^{\text {cond }} A_{\text {abs-iso }}\left(T_{\text {tube }}-T_{\text {iso }}\right)
\end{aligned}
$$

\subsection{The Fluid in the Tube}

$$
\begin{aligned}
m_{f} C P_{f} \frac{d T_{f}}{d t}= & h_{f}^{\text {conv }} A_{\text {tube- } f}\left(T_{\text {tube }}-T_{f}\right) \\
& +n W F\left[S-K\left(T_{f}-T_{a}\right)\right]
\end{aligned}
$$

\subsection{The Insulation Layer}

$$
\begin{aligned}
m_{\text {iso }} C P_{\text {iso }} \frac{d T_{\text {iso }}}{d t}= & h_{\text {iso }}^{\text {cond }} A_{\text {tube-iso }}\left(T_{\text {tube }}-T_{\text {iso }}\right) \\
& +h_{\text {iso }}^{\text {cond }} A_{\text {abs-iso }}\left(T_{a b s}-T_{i s o}\right) \\
& -h_{\text {iso }}^{\text {cond }} A_{\text {abs-iso }}\left(T_{\text {iso }}-T_{a}\right)
\end{aligned}
$$




\section{Energy Balance}

\subsection{Useful Heat Transferred to the Fluid}

The useful heat recoverable in a hybrid collector is determined by the same formula as that of the flat thermal collector.

$$
Q_{u t i l e}=A_{v} F_{t}\left[S-K\left(T_{f e}-T_{a}\right)\right]
$$

The solar radiation used by the thermal system is reduced when compared to a thermal collector alone, since a part of that solar radiation is converted into electricity by the PV cells ${ }^{-}$. Which gives us the coefficient

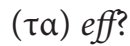

$$
S=(\tau a)_{e f f} G_{i}=\left(\tau_{v} a_{\text {cell }}-\tau_{v} \eta_{P V} \frac{A_{\text {active }}}{A_{v}}\right) G_{i}
$$

Aactive: actual area of capture of PV cells.

The heat transfer factor Ft is given by:

$$
F_{t}=\dot{m}_{f} C_{p f}\left[1-\exp \left(-\frac{F K}{\dot{m}_{f} C_{p f}}\right)\right]
$$

It represents the ratio of the actual thermal flux received by the fluid to that which would be recovered if the absorbing surface was isothermal ${ }^{?}$.

$F$ is the irrigation yield,

$$
F=\frac{1}{K} W\left\{\frac{1}{h_{f}^{\text {conv }} \pi D_{i n t}}+\frac{1}{K\left[D_{e x t}+\left(W-D_{e x t}\right) F^{\prime}\right]}\right\}^{-1}
$$

It corresponds to the ratio of the ambient absorber-air heat resistance to the fluid-air thermal resistance.

$$
F^{\prime}=\frac{\tanh \left(m \frac{W-D_{e x t}}{2}\right)}{m \frac{W-D_{e x t}}{2}}
$$

$$
\text { with } m=\sqrt{\frac{K}{\lambda_{a b s} e_{a b s}}}
$$

The coefficient $K$ is the overall exchange coefficient of the system. It includes losses to the front, back and side of the system. In our case, it is assumed that the side surfaces are well-insulated.

\subsection{Electrical Efficiency and Thermal Efficiency}

The $\mathrm{E}_{\text {elec }}$ electricity production is estimated by the following Equation:

$$
E_{\text {elec }}=A_{v} G_{i} \eta_{P V}
$$

The PV yield is evaluated by the following relation:

$$
\eta_{P V}=\eta_{r e f}\left[1-\beta_{r e f}\left(T_{c e l}-T_{r e f}\right)\right]
$$

The thermal efficiency of the thermal $P V T$ is determined by the following relation?:

$$
\eta_{\text {thq }}=\frac{Q_{\text {utile }}}{A_{v} G_{i}}=F_{t}\left[(\tau \alpha)_{e f f}-K \frac{T_{f e}-T_{a}}{G_{i}}\right]
$$

We then have an overall yield $\eta P V T$ of:

$$
\eta_{P V T}=\frac{E_{\text {elc }}+Q_{\text {utile }}}{A_{v} G_{i}}=\eta_{\text {thq }}+\eta_{P V}
$$

\subsection{Expression of Different Thermal Exchange Coefficients}

\section{$\checkmark$ Convective transfer coefficients}

The convective transfer coefficient $\left(\mathrm{W} / \mathrm{m}^{2} . \mathrm{K}\right)$ of the wind blowing on a glass is given by the following equation ${ }^{10}$ :

$$
h_{v-a}^{c o n v}=2.8+3 . V
$$

Coefficient of convection between the fluid and the tube:

$$
h_{f}^{c o n v}=\frac{\lambda_{f} N u}{D_{\text {int }}}
$$

Or

$$
N u=\left\{\begin{array}{lr}
4.36 & \text { siRe } \leq 2300 \\
0.023 \operatorname{Re}^{0.8} \operatorname{Pr}^{0.33} & \text { siRe }>2300
\end{array}\right.
$$

with $R e=\frac{V D_{\text {int }}}{v}$

$\checkmark$ Conduction transfer coefficients

The transfer coefficient by conduction inside the glass:

$$
h_{v}^{\text {cond }}=\frac{\lambda_{v}}{e_{v}}
$$


The transfer coefficient by conduction between the glass and the cell:

$$
h_{c e l}^{c o n d}=\frac{\lambda_{c e l}}{e_{c e l}}
$$

The transfer coefficient by conduction between the cell and the tedlar:

$$
h_{\text {ted }}^{\text {cond }}=\frac{\lambda_{\text {ted }}}{e_{\text {ted }}}
$$

The transfer coefficient by conduction between the tedlar and the absorber:

$$
h_{a b s}^{\text {cond }}=\frac{\lambda_{a b s}}{e_{a b s}}
$$

The transfer coefficient by conduction between the absorber and the insulator:

$$
h_{i s o}^{\text {cond }}=\frac{\lambda_{i s o}}{e_{i s o}}
$$

The transfer coefficient by conduction between the absorber and the tube:

$$
h_{\text {tube }}^{\text {cond }}=\left(\frac{e_{a b s}}{\lambda_{a b s}}+\frac{\frac{D_{e x t}-D_{\text {int }}}{2}}{\lambda_{a b s}}\right)^{-1}
$$

and

$$
A_{a b s-t u b e}=A_{v} \frac{W-D_{e x t}}{W} ; A_{a b s-i s o}=A_{v}\left(1-\frac{W-D_{e x t}}{W}\right)
$$

\section{Digital System Resolution}

One of the important aspects of solving the problem is the calculation of the temperatures of the different layers of the system. This ends to solving the system of differential equations formed by Equations (1) to (8).

\subsection{Assumptions}

Before calculations, certain hypotheses are necessary:

- The heat transfer from the collector edges is negligible.

- The physical properties of materials are not temperature dependent.

- Mass flow is uniform in the collector tubes.
- The temperatures of the PVT collector components are a function of time.

- Dust and dirt on the collector are negligible.

- The energy flow received by the collector is a function of time.

- Heat transfer is considered in one dimension through the layers of the system.

- The physical properties of the fluid are a function of the temperature.

- The wind speed on the face of the collector is assumed to be constant.

Other simplifying assumptions

In practice, the variation of the enthalpy with time of the components of the collector is small, that is to say that the terms in miCpi can be neglected. We can thus make the hypothesis of a quasi-stationary operation of the collector. This hypothesis has the consequence of simplifying the equations without however masking the temporary evolution of the phenomena which remain linked to the variable solar flux in the time ${ }^{11}$.

The Cholesky method was used to solve this system of equations.

The simulation was done under MATLAB.

\subsection{Flowchart}

The resolution flowchart is shown in Figure 1, 2.

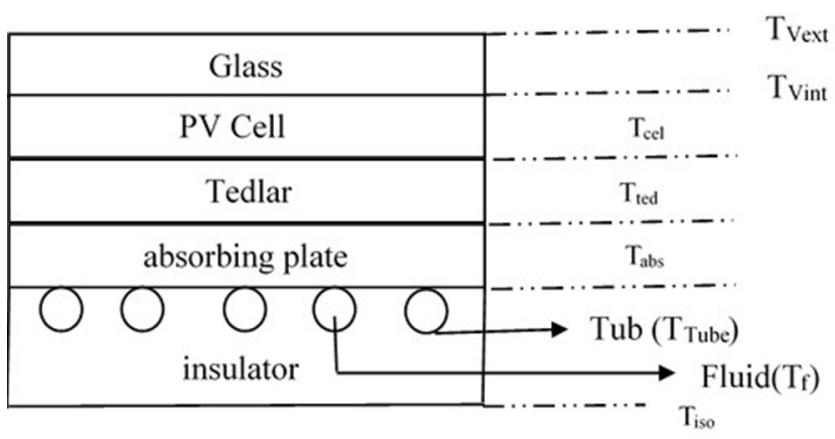

Figure 1. PVT collector model.

\section{Results and Discussions}

\subsection{Radiance}

Figure 3 shows the evolution of simulated solar radiation. It is obtained by software (PVgis from its sunshine maps) for the city of Ouagadougou. 


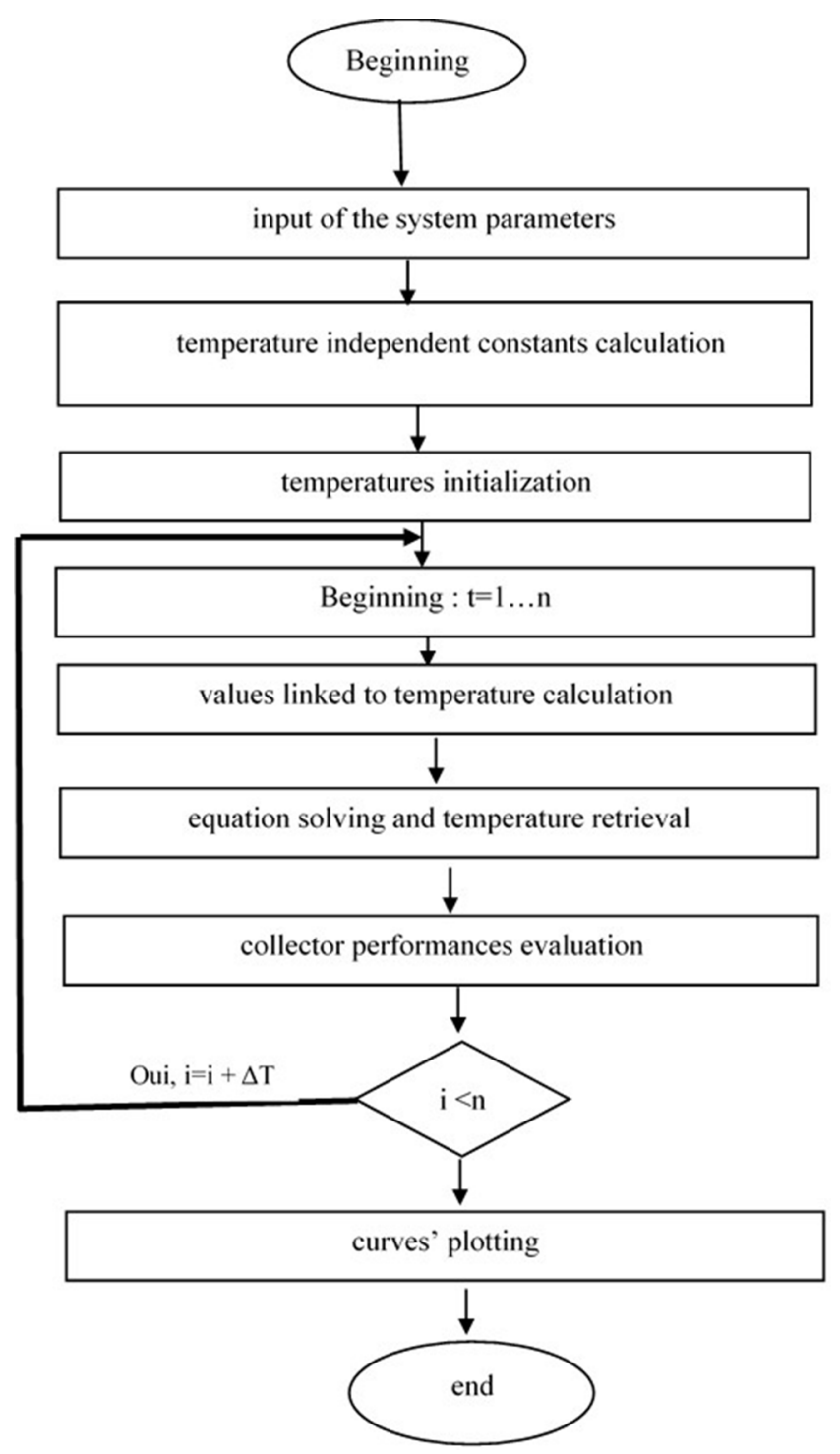

Figure 2. Flowchart of the simulation program.

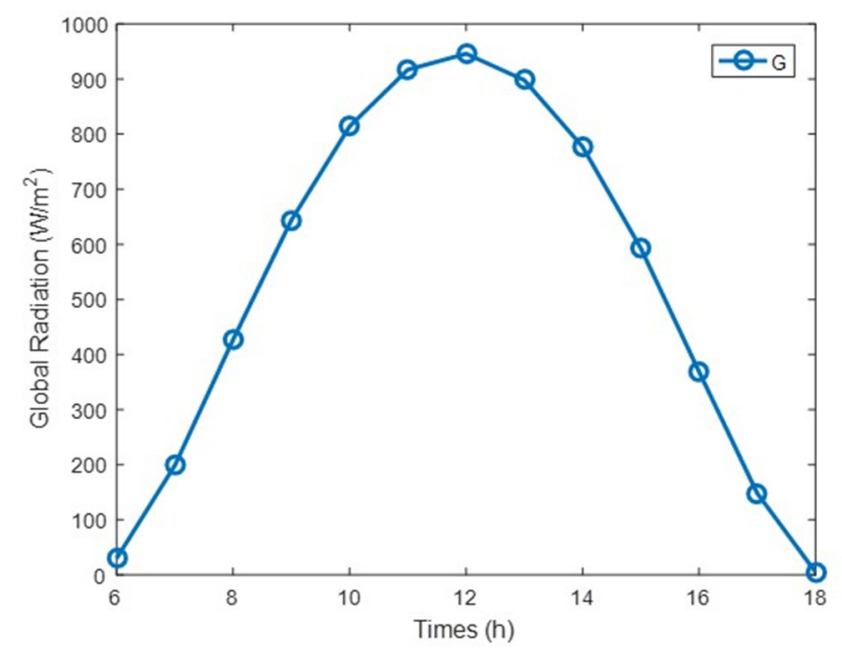

Figure 3. Global solar radiation.
The radiation curve is well bell-shaped. The maximum radiation is between $11 \mathrm{~h}$ and $13 \mathrm{~h}$ with a peak of nearly $950 \mathrm{~W} / \mathrm{m}^{2}$.

\subsection{Ambient Temperature and Sky Temperature}

Figure 4 shows the evolution of the celestial vault temperature and that of the ambient with time.

The ambient temperature was obtained by meteorological station data for the day considered for the simulation. We note the similarity between the curve of the ambient temperature and that of the sky. The equation giving the temperature of the sky according to the ambient temperature is as follow:

$$
T_{\text {ciel }}=0.0552 T^{1,5}
$$

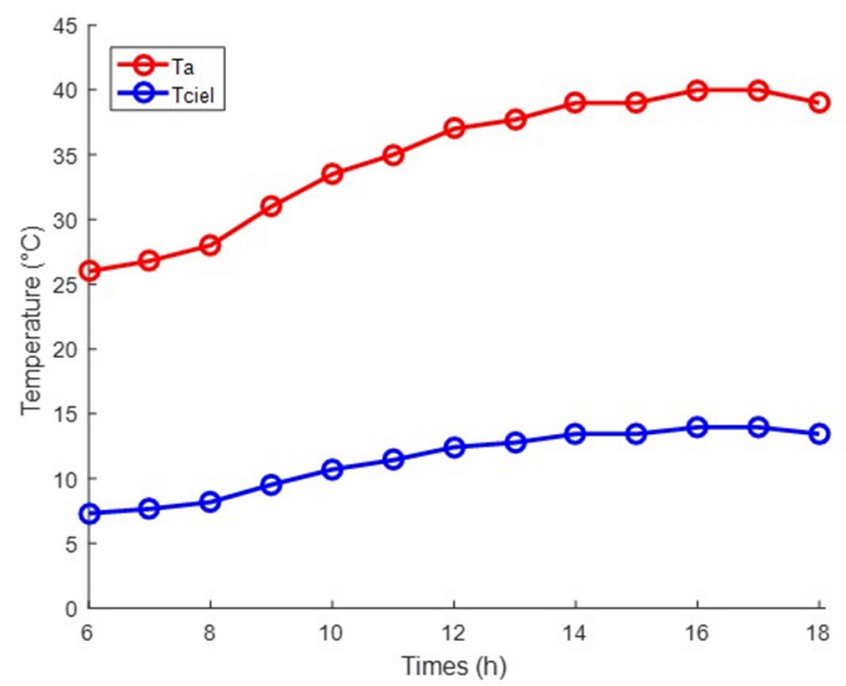

Figure 4. Ambient and sky temperature.

\subsection{Temperature of Collector Elements}

Figure 5 shows the temperature evolution of the different elements of the collector with time.

The temperature of the insulation has the same pace as the ambient temperature. This is perfectly normal since the insulation is sized to prevent heat exchange between the collector and the environment.

The temperature of the glass is lower than that of the elements inside the collector such as the absorber and the PV cell. Here we notice a heating of the PV cell. This will lead to the reduction of its output as well as the electric power produced. However, we will recover a significant amount of heat that will increase the overall energy efficiency of the collector as we will see later. 


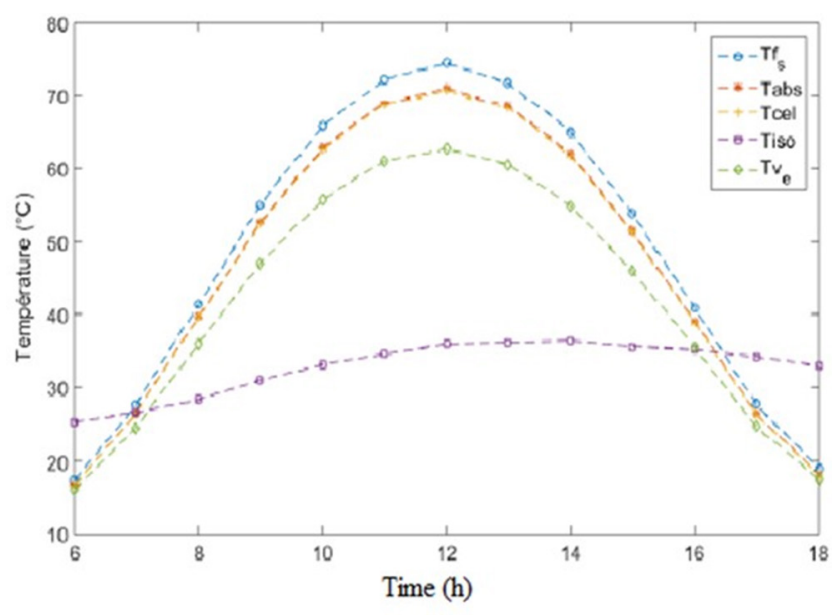

Figure 5. Temperature profile of the different collector elements.

\subsection{Influence of Wind Speed on Temperature Profiles}

Figures 6 and 7 respectively show the temperature profiles of the collector elements at wind speeds of 2 $\mathrm{m} / \mathrm{s}$ and $5 \mathrm{~m} / \mathrm{s}$. We first notice that the temperature of the insulation remains constant. This explains that the insulation is not disturbed by the outer parameters. On the other hand, the other temperatures experienced a significant decrease of approximately $5^{\circ} \mathrm{C}$ due to the increase of the coefficient of convection exchange of the outer pane with the air. Increasing the wind speed therefore causes the collector to cool down.

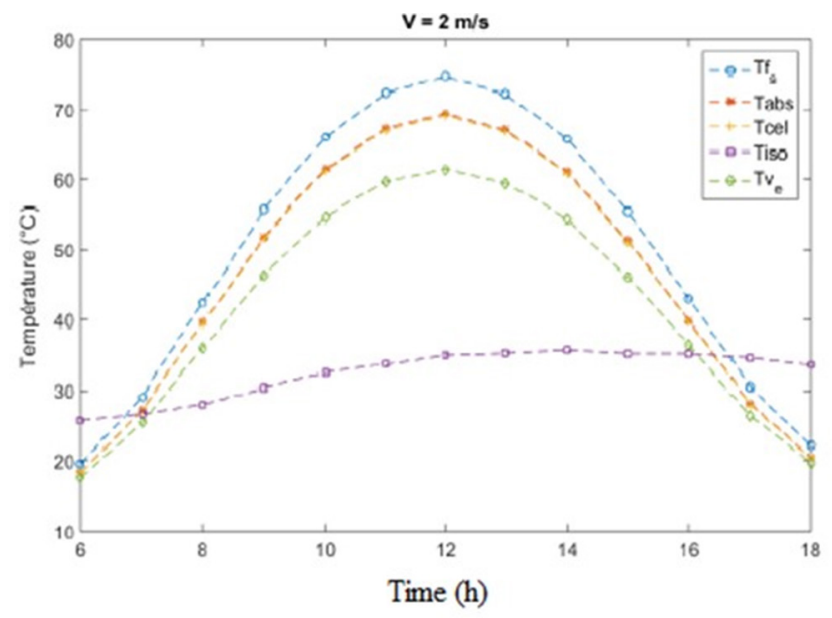

Figure 6. Temperature profile for a wind of $2 \mathrm{~m} / \mathrm{s}$.

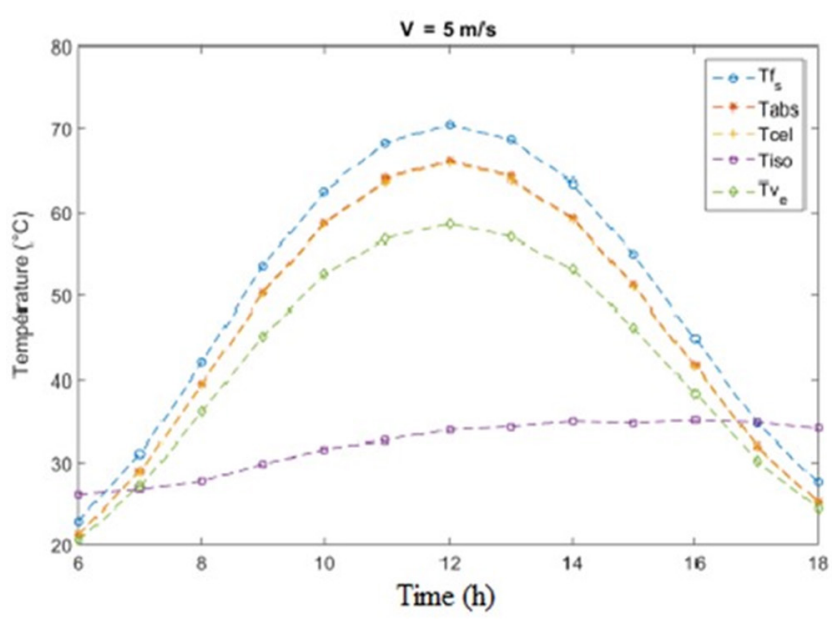

Figure 7. Temperature profile for a wind of $5 \mathrm{~m} / \mathrm{s}$.

\subsection{Influence of the Flow of Water Used}

Figure 8 shows the evolution of fluid temperature with water flow. The increase in the water flow brings a decrease in the temperature of the fluid in the tube. This increase brings an increase in the speed of the water in the tube, causing the decrease of the convective exchange coefficient of the water. The amount of heat received by the water is then reduced as is its temperature.

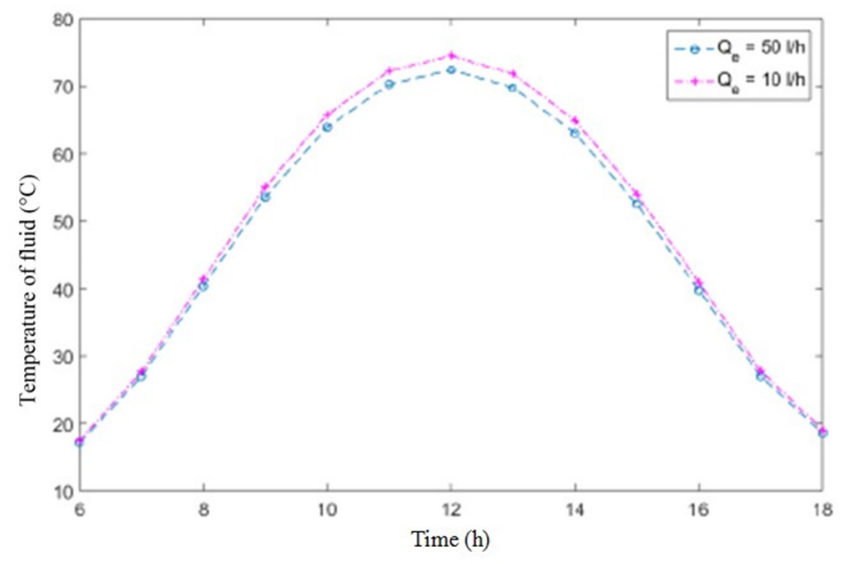

Figure 8. Influence of water flow on fluid temperature.

\section{Power and Electrical Efficiency}

Figure 9 illustrates the electric powers supplied by the PV and PVT collectors of the same power $(250 \mathrm{Wc})$. The two powers curves have the same shape, but that the PVT collector provides a power slightly lower than the power of 
a PV panel alone. This is mainly due to the venting of the back of the PV module, evacuating the excess heat. On the other hand, for the PVT collector, we see a heat of the panel due to the fact that the heat is conveyed by the coolant in the absorber when there is thermal insulation at the back of the panel. This then causes a decrease in the electrical power supplied. These results are consistent with those of the literature ${ }^{8}$.

The corresponding electrical efficiency is shown in Figure 10.

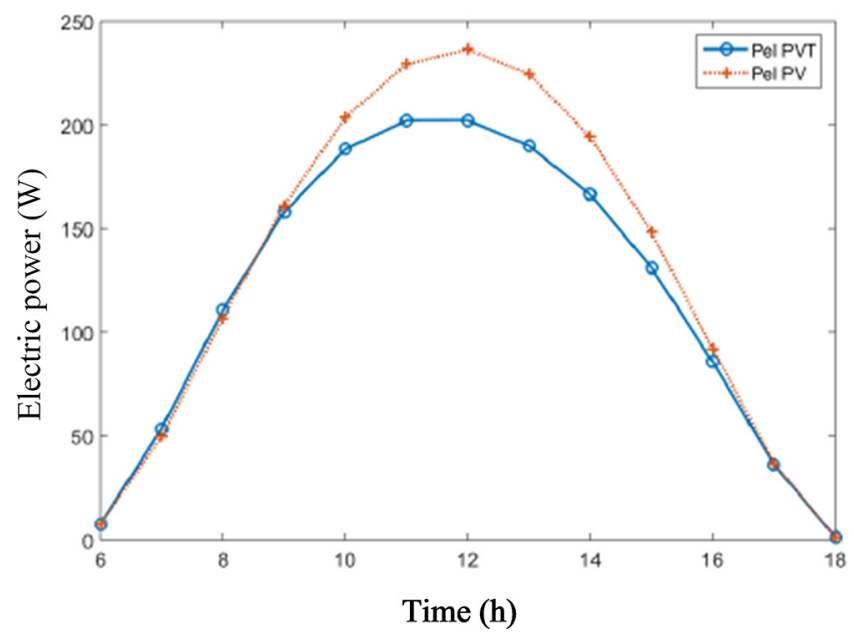

Figure 9. Electrical power provided by the PVT collector and a PV collector.

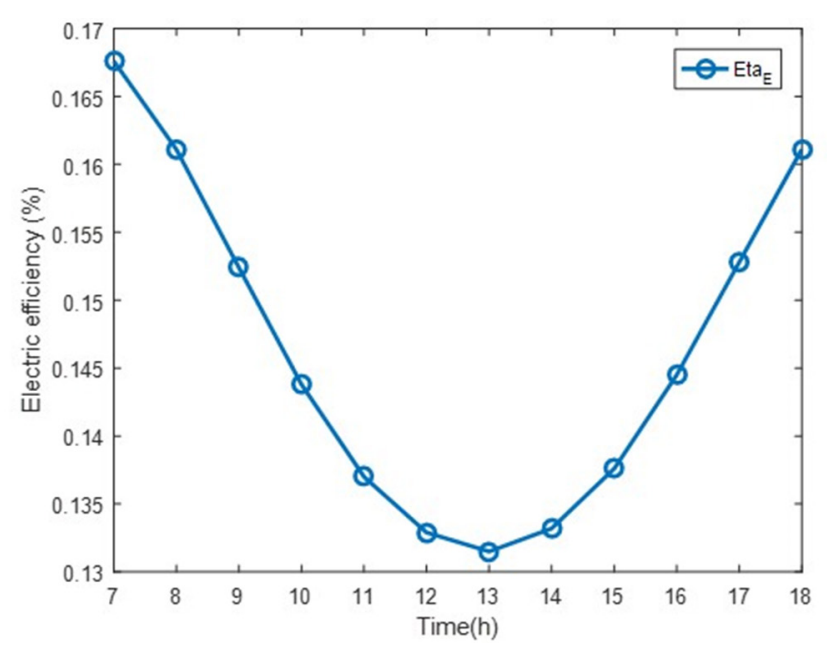

Figure 10. PVT collector electrical performance.

\section{Power and Thermal Efficiency}

Figures 11 and 12 respectively represent the useful thermal power and the thermal efficiency of a PVT collector.

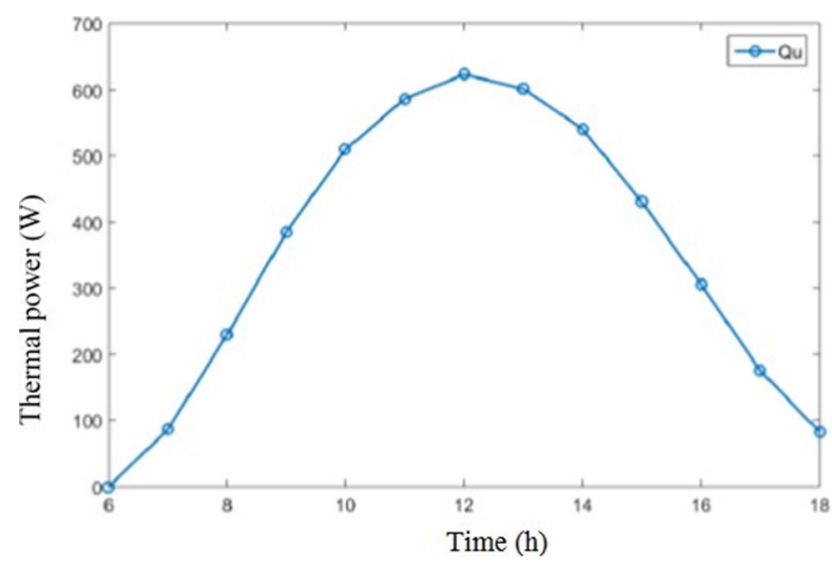

Figure 11. Useful heat output.

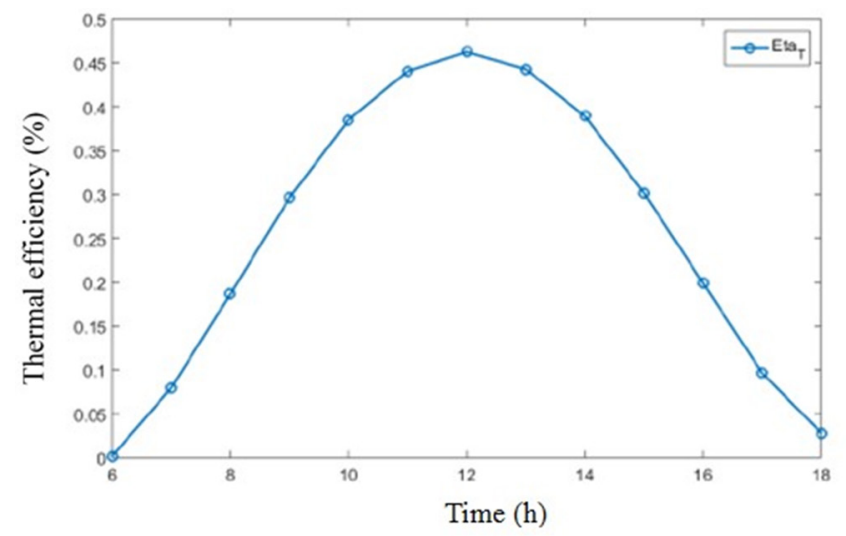

Figure 12. Thermal performance.

The recoverable thermal power of a PVT collector varies throughout the day with a maximum at 12 hours which corresponds to the maximum value of sunshine. This power is closely related to the flow of water in the tubes under the absorber and will be felt on the overall efficiency of the collector.

\section{Overall Performance}

The overall yield is shown in Figure 13. The overall efficiency of the PVT collector rises up to $57 \%$ at 12 o'clock when the sun is at its maximum. This overall efficiency is much higher than the efficiency of a PV collector alone. In cogeneration, a PVT collector will not produce more electrical energy than a PV collector alone but its overall energy efficiency is much greater. 


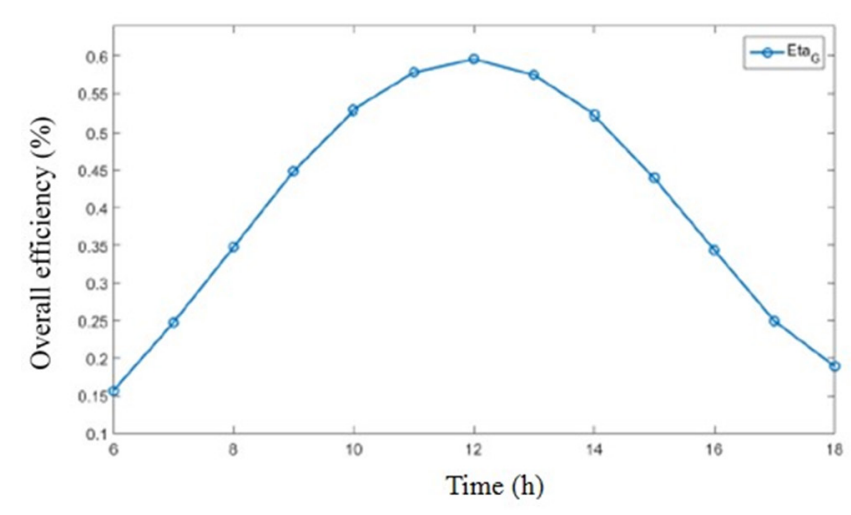

Figure 13. Overall PVT collector performance.

\section{Conclusion}

The simulation of the problem in Matlab gave us interesting results. We obtained the temperature profiles of the different layers of the collector and we determined the electrical energy as well as the thermal energy that could be collected from a PVT collector. These results show that the PVT collector gives better performance (overall) than each isolated system that is to say PV collector and thermal collector.

\section{References}

1. Zondag HA, de Vries DW, vanHelden WGJ, van Zolingen RJC, van Steenhoven AA. The yield of different combined PV-thermal collector design. Solar Energy. 2003; 74(3): 253-269. https://doi.org/10.1016/S0038-092X(03)00121-X

2. Touafek K, Malek A, Haddadi M. Etude expérimentale du capteur hybride photovoltaique thermique. Revue des Energies Renouvelables. 2006; 9(13):143-54.
3. Khelifa A, Touafek K. Etude de l'influence des paramètres externes et internes sur le capteur hybride Photovoltaïque Thermique (PVT). Revue des Energies Renouvelables. 2012; 15(11):67-75.

4. Boulfaf N, Chaoufi J, Ghafiri A, Elorf A. Thermal Study of Hybrid Photovoltaic Thermal (PV-T) solar air collector using finiteelement method. International Journal of Renewable Energy Research. 2016; 6(1):1-12.

5. Ghellab A, Kaabi A, Annane S, Brieche C. Les retombées technico-économiques d'un capteur hybride photovoltaïque/ thermique à air. Revue des Energies Renouvelables. 2013; 16(13):425-40.

6. Jahromia SN, Vadiee A, Yaghoubi M. Exergy and economice valuation of a commercially available PV/T collector for different climates in Iran. Energy Procedia. 2015; 75: 444-56. https://doi.org/10.1016/j.egypro.2015.07.416

7. Nougblega Y, Dupre JC, Atchonouglo K, Germaneau A, Hesser F, Banna M, Napo K, Chaoufi J, Vallée C et Straboni A. Conception et réalisation des capteurs hybrides photovoltaïque-thermiques sous vide ou avec lame d'air confinée. Afrique Science. 2015; 11(12):12-23.

8. Ben cheikh el Hocine $H$, Touafek $K$, Kerrour F, Haloui $\mathrm{H}$ et Khelifa A. Model validation of an empirical Photovoltaic Thermal (PV/T) collector. Energy Procedia. 2015; 74: 1090-9. https://doi.org/10.1016/j.egypro.2015. 07.749

9. Bernard J. Energie solaire. Calculs et optimization. Paris: Ellipse; 2011. p. 1-283.

10. Duffie JA, Beckman WA. Solar engineering of thermal processes. 4th ed. Hoboken, New Jersey: John Wiley \& Sons Inc; 2013. p. 1-936. https://doi.org/10.1002/9781118671603 https://doi.org/10.1002/9781118671603.part1

11. Tabet I. Étude, Réalisation et simulation d'un capteur solaire. Thèse de doctorat. Université des frères mentouri Constantine; 2016. p. 1-179. 